\title{
Thymic Carcinoma: Involvement of Great Vessels Indicates Poor Prognosis
}

\author{
Yau-Lin Tseng, MD, Shan-Tair Wang, PhD, Ming-Ho Wu, MD, Mu-Yen Lin, MD, \\ Wu-Wei Lai, MD, and Fen-Fen Cheng, MD
}

Institute of Clinical Medicine, Department of Surgery, Institute of Public Health, Thoracic Division and Department of Pathology, National Cheng Kung University Hospital, College of Medicine, Tainan, Taiwan, ROC

Background. Thymic carcinoma is a rare, indolent, and invasive cancer. This study investigated the treatment results of thymic carcinoma and clinical prognostic factors.

Methods. From June 1988 to January 2002, 38 patients were enrolled in this study with the diagnosis of thymic carcinoma in the Cheng-Kung University Hospital based on Rosai's and Muller-Hermelink's classification. Clinical and pathologic data were retrospectively reviewed. Survival analysis was performed using the KaplanMeier, log rank, and Wilcoxon tests. Statistical significance was defined as $p<0.05$.

Results. Pathology revealed 14 poorly differentiated, 6 moderately differentiated, and 8 well-differentiated squamous cell carcinomas; 8 lymphoepithelioma-like carcinomas; and 2 other carcinomas. Pathologic staging using the Masaoka system included 6 stage II, 23 stage III, and 9 stage IV patients. Six biopsies, five debulkings,

$\mathrm{T}$ hymic carcinoma is a rare, indolent, and invasive cancer that easily metastasizes. It constitutes a heterogeneous group of tumors that display different biological behavior and prognosis [1-6]. Chung [7] collected all the reports available through Medline from 1966 to 2000; only 305 patients with thymic carcinoma had been reported. Most of these patients were asymptomatic or had late symptoms develop and were treated in the late stages of the disease. Reports about the clinical prognostic factors and treatment of choice are rare because most series have a limited number of patients [8-11]. Some reports suggest that tumor resectability, tumor stage, tumor grading, or postoperative radiotherapy influenced the outcome $[4,6,8-11]$. The largest clinical report by Blumberg and colleagues [12] showed that innominate vessel invasion was the only prognostic factor and that Masaoka stages could not predict prognosis. We treated 40 patients with thymic carcinoma from July 1988 to January 2002, and we reported that thymic carcinomas had a high percentage of bcl-2 and mcl-1 expression [13, 14], which indicated their malignant behavior. Those

Accepted for publication April 8, 2003.

Address reprint requests to Dr Wu, Department of Surgery, National Cheng Kung University Hospital, No 138, Sheng-Li Rd, Tainan 70428, Taiwan, ROC; e-mail: tsengyl@mail.ncku.edu.tw. and 27 complete resections were performed. All patients were followed from 15 months to 10 years 9 months, with an average of $\mathbf{5 3 . 8}$ months. Median survival time was 81 months, and median recurrence time was 52 months. Eighteen patients are still alive, and 7 are alive with disease. Well-differentiated squamous cell carcinoma had better prognosis than other carcinomas $(p=0.022)$. Complete resection significantly increased survival rate $(p<0.001)$. Tumor invasion of the superior vena cava, pulmonary vessels, or aorta were significant predictors for poor prognosis $(p=0.016,0.002$, and 0.002 , respectively).

Conclusions. Only patients with thymic carcinoma who underwent complete resection had long-term survival. Prognosis of thymic carcinoma seemed mainly dependent on tumor invasion of the great vessels.

(Ann Thorac Surg 2003;76:1041-5)

(C) 2003 by The Society of Thoracic Surgeons

patients, especially with stage III tumors involved in a wide range of different mediastinal organs, were aggressively treated by surgery. We had a relatively large number of patients with thymic carcinoma and a high percentage and high complete resection rate of stage III patients. Thus, we retrospectively reviewed our data to define the prognostic factors and the influence of aggressive surgical treatment of thymic carcinoma.

\section{Material and Methods}

\section{Patient Selection}

Medical records of the patients treated for anterior mediastinal tumors at the National Cheng Kung University Hospital from June 1988 to January 2002 were reviewed. Patients diagnosed with thymic carcinoma based on Rosai's and Muller-Hermelink's classification, which was classified as the type C thymoma by World Health Organization, were included in this study. All the diagnoses of patients with thymoma and thymic carcinoma were re-revised by a pathologist. Thymic carcinoid was excluded from this study. The clinical and pathologic data of those patients were retrospectively reviewed from the chart and telephone contact was made with patients or their families. All patients were followed-up for at least 15 months or until the time of their death. 


\section{General Management Principles for Thymic Carcinoma}

Computed tomography or magnetic resonance imaging was used to evaluate whether the lesions were resectable. The criteria for considering a tumor to be unresectable at the start of the study were (1) association with superior vena cava syndrome; (2) association with hoarseness; (3) association with pleural effusion or phrenic nerve paralysis; (4) association with pericardial effusion, and encasement of the great vessels of mediastinum (including pulmonary vessels, aorta, or innominate artery), or a combination thereof. Reconstructive procedures of the superior vena cava (SVC) were the described the same as in our previous report [15]. Biopsy was performed by mediastinoscopy or mediastinotomy for unresectable lesions. Preoperative concurrent chemoradiation therapy using the cisplatin-based regimens along with radiation therapy was performed to downstage the unresectable tumor. If the tumor showed progressive downstage, operative procedures were subsequently performed. Debulking surgery was performed to decrease tumor load for further adjuvant therapy in a limited time. Postoperative radiation therapy with a full dose (5000 to $6000 \mathrm{cGy}$ ) was routinely performed for those patients undergoing complete resection.

\section{Statistical Analysis}

The clinical data used for analysis included age, sex, tumor size, tumor staging, cell type of tumor, operative procedures (complete resection versus incomplete resection), and local invasion of organs (lung, pericardium and pericardial effusion, pleura and pleural effusion, phrenic nerve, recurrent laryngeal nerve, innominate vein, SVC, pulmonary vessels, aorta, paratracheal lymph nodes, perithymic lymph nodes). Survival analysis was performed using the Kaplan-Meier, univariable log rank, and Wilcoxon tests. Statistical significance was defined as $p$ less than 0.05 .

\section{Results}

\section{Incidence of Thymic Carcinoma}

From June 1988 to January 2002, of the 298 patients with anterior mediastinal tumors, 40 patients (13.4\%) were diagnosed with thymic carcinoma. The incidence of thymic carcinoma among all thymic malignant neoplasms requiring surgery was $33.9 \%$ (40 of 118 ).

\section{Patient Characterization}

One patient with thymic carcinoid and 1 lost to follow-up immediately after operation were excluded from this study. The patients enrolled in this study consisted of 19 males and 19 females, ranging in age from 25 to 77 years (average, $53.5 \pm 2.1$ years old). Pathology revealed 14 poorly-differentiated, six moderately-differentiated, and eight well-differentiated (WD) squamous cell carcinomas (SCC); eight lymphoepithelioma-like carcinomas; one spindle cell carcinoma, and one undifferentiated carcinoma. Pathologic staging according to the Masaoka sys-
Table 1. Stage and Cell Type of Thymic Carcinoma Related to Tumor Resectability

\begin{tabular}{|c|c|c|c|}
\hline Masaoka Stage & $\begin{array}{c}\text { Total No. } \\
\text { of } \\
\text { Patients } \\
(\%)\end{array}$ & $\begin{array}{l}\text { En Bloc } \\
\text { Resection } \\
\text { No. of } \\
\text { Patients } \\
(\%)\end{array}$ & $\begin{array}{l}\text { Incomplete } \\
\text { Resection } \\
\text { No. of } \\
\text { Patients } \\
(\%)\end{array}$ \\
\hline IIa & $5(13)$ & $5(100)$ & $0(0)$ \\
\hline $\mathrm{IIb}$ & $1(3)$ & $1(100)$ & $0(0)$ \\
\hline III & $23(60)$ & $19(83)$ & 4 (17) \\
\hline IVa & $4(11)$ & $0(0)$ & $4(100)$ \\
\hline $\mathrm{IVb}$ & $5(13)$ & $2(40)$ & $3(60)$ \\
\hline \multicolumn{4}{|l|}{ Pathology } \\
\hline $\begin{array}{l}\text { Well-differentiated } \\
\text { squamous cell carcinoma }\end{array}$ & $8(21)$ & $8(100)$ & $0(0)$ \\
\hline $\begin{array}{l}\text { Moderately-differentiated } \\
\text { squamous cell carcinomas }\end{array}$ & $6(16)$ & $4(67)$ & $2(33)$ \\
\hline $\begin{array}{l}\text { Poorly-differentiated } \\
\text { squamous cell carcinomas }\end{array}$ & $14(37)$ & $8(57)$ & $6(43)$ \\
\hline $\begin{array}{l}\text { Lymphoepithelioma-like } \\
\text { carcinomas }\end{array}$ & $8(21)$ & $5(63)$ & $3(37)$ \\
\hline Other $^{\mathrm{b}}$ & $2(5)$ & $2(100)$ & $0(0)$ \\
\hline
\end{tabular}

a Four patients had thymic carcinoma combined with cortical thymoma. Three of these patients were in stage IIa and 1 was in stage IIb. Four other patients had combined myasthenia gravis; $\quad{ }^{b}$ Other includes one spindle cell carcinoma and one undifferentiated carcinoma.

tem and their relationship to operative procedures are shown in Table 1. Incidence of locoregional invasion of the tumor and prognosis are shown in Table 2. The patients with tumor invasion of the SVC, pulmonary vessels, and aorta had significantly poorer prognosis.

Prognostic factors according to tumor staging, cell type, and operative procedures (complete versus incomplete resection) are shown in Table 3 . The patients with WD SCC had a better prognosis compared with other types of thymic carcinoma. Complete resection of the tumor significantly improved the survival rate of the patients.

\section{Responses to Radiotherapy and Chemotherapy}

Seven patients underwent concomitant chemoradiation therapy after confirmation of tumor from biopsy. The tumors of 2 patients had changed from stage IVb to III, and the patients subsequently underwent complete resections. One patient with tumor invasion of the aorta had decreased tumor volume. This patient eventually died from intraoperative aortic rupture. Three patients showed only slight decreasing volume of the tumor.

\section{Recurrence of Cancer}

Recurrence of cancer was noted in 13 of 27 patients with en-bloc resection. Nine patients had recurrence in the pleural cavity, whereas 7 patients had distant metastasis. The median interval of recurrence was 52 months (95\% confidence interval, 30 to 80 months).

\section{Reoperation for Local and Distant Recurrence}

Reoperation for recurrence was performed on 2 patients with pleural recurrence and 1 patient with lung metastasis. Two patients with stage III WD SCC who underwent 
Table 2. Distribution of Locoregional Invasion and Prognostic Predictors of Survivals Among 38 Patients Using Log Rank Test

\begin{tabular}{|c|c|c|}
\hline Site & Invasion (No.) & Significance $^{a}$ \\
\hline Pericardium & $\begin{array}{l}\text { No (12) } \\
\text { Yes (26) }\end{array}$ & NS \\
\hline Pericardial effusion & $\begin{array}{l}\text { No (31) } \\
\text { Yes (7) }\end{array}$ & NS \\
\hline Phrenic nerve & $\begin{array}{l}\text { No (26) } \\
\text { Yes (12) }\end{array}$ & NS \\
\hline Recurrent laryngeal nerve & $\begin{array}{l}\text { No (33) } \\
\text { Yes (5) }\end{array}$ & NS \\
\hline Lung & $\begin{array}{l}\text { No (12) } \\
\text { Yes (26) }\end{array}$ & NS \\
\hline Innominate vein & $\begin{array}{l}\text { No (15) } \\
\text { Yes (23) }\end{array}$ & NS \\
\hline Superior vena cava ${ }^{b}$ & $\begin{array}{l}\text { No (27) } \\
\text { Yes (11) }\end{array}$ & $p=0.016$ \\
\hline Pleural seeding & $\begin{array}{l}\text { No (35) } \\
\text { Yes (3) }\end{array}$ & NS \\
\hline Pleural effusion & $\begin{array}{l}\text { No (35) } \\
\text { Yes (3) }\end{array}$ & NS \\
\hline Aorta $^{b}$ & $\begin{array}{l}\text { No (30) } \\
\text { Yes (8) }\end{array}$ & $p=0.002$ \\
\hline Pulmonary vessels ${ }^{\mathrm{b}}$ & $\begin{array}{l}\text { No (31) } \\
\text { Yes (7) }\end{array}$ & $p=0.002$ \\
\hline Parathymic lymph nodes & $\begin{array}{l}\text { No (29) } \\
\text { Yes (9) }\end{array}$ & NS \\
\hline Paratracheal lymph nodes & $\begin{array}{l}\text { No (35) } \\
\text { Yes (3) }\end{array}$ & NS \\
\hline
\end{tabular}

a Significance: $p<0.05 ; \quad \mathrm{b}$ Tumor invasion of the superior vena cava aorta, and pulmonary vessels was also a significant predictor for poor prognosis using the Wilcoxon test $(p=0.016, p=0.002$, and $p=0.002$, respectively).

NS = not significant.

complete resection of tumors had pleural recurrence at 3 years 14 months, respectively. They underwent en-bloc resection of the multiple pleural tumors and had recurrence in the pleural cavity again at 7 years 8 months and at 3 years, respectively, and were again treated with radiotherapy. They were still alive at 10 years 6 months and at 8 years 10 months, respectively. One patient with stage III lymphoepithelioma-like carcinoma who underwent complete resection had a recurrence on bilateral lungs 3 years later. He underwent bilateral lung wedge resection and tumor enucleation. Two years later, right lung recurrence was noted and he underwent right pneumonectomy. He was still alive without recurrence at follow-up at 7 years 3 months.

\section{Outcome}

The cumulative survival of all patients (those with complete resection and those who were not completely resected) using the Kaplan-Meier method is shown in Figure 1. All patients were followed-up from 1 year 3 months to 10 years 9 months (average follow-up, 54.3 months). Median survival time was 81 months $(95 \%$ confidence interval, 46 months, not obtainable). Eighteen
Table 3. Survival Factors Including Stage, Tumor Resectability, Postoperative Radiotherapy, Preoperative and Postoperative Chemotherapy, and Cell Type of Tumor Using Log Rank Test

\begin{tabular}{|c|c|c|}
\hline & Patients (No.) & Significance $^{a}$ \\
\hline \multicolumn{3}{|l|}{ Stage } \\
\hline II & 6 & \multirow[t]{3}{*}{ NS } \\
\hline III & 23 & \\
\hline IV & 9 & \\
\hline \multicolumn{3}{|l|}{ Surgery } \\
\hline Complete resection & 27 & \multirow[t]{2}{*}{$p<0.001$} \\
\hline Incomplete resection $^{\mathrm{b}}$ & 11 & \\
\hline \multicolumn{3}{|l|}{ Radiotherapy } \\
\hline \multirow[t]{2}{*}{ Postoperative } & No (10) & \multirow[t]{2}{*}{ NS } \\
\hline & Yes (28) & \\
\hline \multicolumn{3}{|l|}{ Chemotherapy } \\
\hline \multirow[t]{2}{*}{ Preoperative } & No (35) & \multirow[t]{2}{*}{ NS } \\
\hline & Yes (3) & \\
\hline \multirow[t]{2}{*}{ Postoperative } & No (29) & \multirow[t]{2}{*}{ NS } \\
\hline & Yes (9) & \\
\hline \multicolumn{3}{|l|}{ Cell type ${ }^{c}$} \\
\hline $\begin{array}{l}\text { Well-differentiated squamous } \\
\text { cell carcinomas }\end{array}$ & 8 & \multirow[t]{2}{*}{$p=0.022$} \\
\hline Other & 30 & \\
\hline \multicolumn{3}{|c|}{$\begin{array}{l}\text { a Significance: } p<0.05 ; \quad{ }^{\mathrm{b}} \text { Incomplete resection included biopsy, peri- } \\
\text { cardiectomy, and debulking procedures. }{ }^{\mathrm{c}} \text { Cell types other than well- } \\
\text { differentiated squamous cell carcinoma and incomplete resection of } \\
\text { tumor were also significant poor prognostic factors using Wilcoxon test }(p \\
=0.043, p<0.001 \text { ); }\end{array}$} \\
\hline \multicolumn{3}{|l|}{ NS $=$ not significant. } \\
\hline
\end{tabular}

patients are still alive, and 7 of them are living with the disease. Seventeen of the 21 patients died from cancer itself or from complications from cancer and its related treatment, such as radiotherapy-induced respiratory or cardiac failure. The other 4 patients died from other reasons, including 3 operative complications (aortic rup-

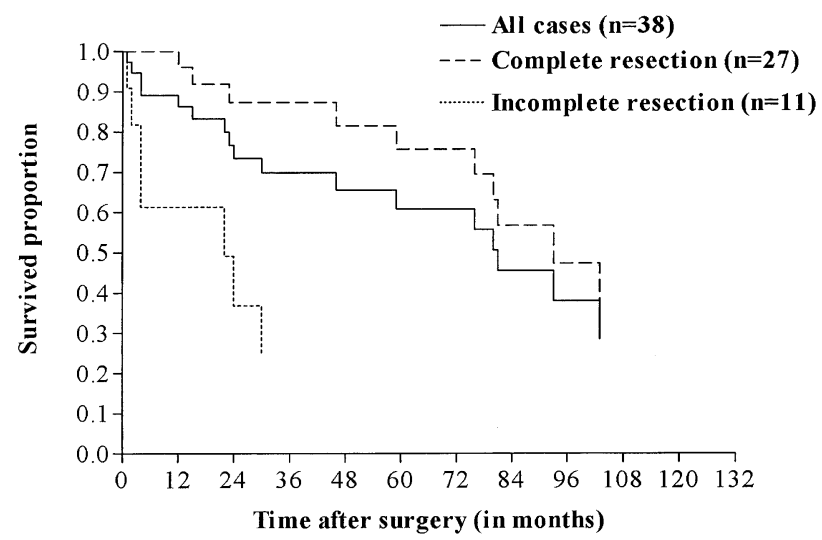

Fig 1. The cumulative survival rate of all 38 patients, those patients with complete resection and those with incomplete resection by Kaplan-Meier analysis. There was significant survival difference between those patients with tumor complete resection and those without complete resection $(\mathrm{p}<0.001$ by $\log$ rank and $\mathrm{p}<0.001$ by Wilcoxon method). 
ture, ventricular tachycardia, and aspiration pneumonia) and 1 acute myocardial infarction, which made the surgical mortality $10.5 \%$.

\section{Comment}

Thymic carcinoma is a very rare, malignant tumor. Its rarity, invasiveness, and high rate of recurrence make this tumor respond poorly to treatment. Herein we reported one of the largest series published thus far. The prevalence of thymic carcinoma compared with all thymic malignant neoplasms was similar to the reports by Hsu and colleagues [11] and Blumberg and colleagues [12]. In Taiwan, the incidence of thymic carcinoma seems higher than in Western countries [8-11].

Squamous cell carcinoma was the most common type of thymic carcinoma in this series followed by lymphoepithelioma -like carcinomas. Although there are reports in the literature $[8,9]$ that SCC had a better prognosis than other histologic types of thymic carcinoma, our results did not show this tendency. Contrary to Blumberg and colleagues' [12] report, our data revealed that the prognosis of WD SCC was better than other types of thymic carcinoma. Well-differentiated SCC was defined as low-grade malignancy and was reported as the most reliable predictor of prognosis [4, 6, 9]. As for other reports [2, 12], myasthenia gravis only occurred in the patients who had thymic carcinoma with the cell type of WD SCC, and the incidence was high in this series [12]. This may be the reason that WD SCC was found earlier than other types of thymic carcinoma. Our data also showed that the patients who had thymic carcinoma combined with cortical thymoma all occurred within the stage II WD SCC group. Thus, we believe that WD SCC may be a closer spectrum of differentiation and prognosis to thymoma rather than to thymic carcinoma $[6,16,17]$.

We performed debulking surgery in some of the patients because this procedure has been suggested to increase survival time. In our limited experiences, debulking itself seemed to increase morbidity and mortality, especially when the recurrent laryngeal nerve or phrenic nerve was sacrificed. Two of 6 patients who underwent debulking surgery eventually died from aspiration pneumonia and respiratory failure, respectively. Two other patients died from operative complications (aortic rupture and ventricular tachycardia). The efficacy and limit of debulking surgery is still questionable. It is hard to decide which kind of patients would get benefit from debulking surgery, because all of them had unresectable tumor. Our suggestion is that during debulking surgery it may be better to preserve the functional nerve (vagus nerve, recurrent laryngeal nerve, or phrenic nerve); even the nerve is encased by tumor to prevent postoperative complications. Complete resection of tumor was a significant prognostic factor of survival in this series, contrary to some reports $[11,12]$. Size of tumor did not influence the tumor resectability or the survival rate. In our experience, only the patients undergoing complete resection of the tumor had long-term survival. Our cumulative survival result was almost the same as Blum- berg and colleagues' [12] report, and was better than most serial reports $[8,9,11]$. This suggests that aggressive surgery must play a role in increasing survival rate. Reports discussing the role of reoperation for thymic carcinoma recurrence are rare. In this series, the results are very interesting; however, this deserves further investigation because the experience is limited.

Although preoperative adjuvant therapy has been reported to increase tumor resectability, or even cure patients [18, 19], we had dismal experiences, similar to other reports from Taiwan [8-11]. There may be a racial difference in the response of thymic carcinoma to treatment. The response was only partial in two-thirds of patients, and no complete response was noted. Two patients had cervical lymph node metastasis that disappeared after neoadjuvant therapy, and underwent complete resection of mediastinal tumors and cervical lymph node dissection. Occipital lymph node metastasis occurred 6 months after surgery in 1 of 2 patients, and this patient died soon after recurrence. The other patient has been followed-up for 15 months without recurrence.

Local regional invasion of nearby organs by thymic carcinoma is very common, and the lung was most commonly invaded. Our results showed tumor invasion of SVC was one of the major determinants of prognosis, which was similar to the result reported by Blumberg and colleagues [12]. However, invasion of the SVC did not preclude surgery. If the tumor invading the SVC could be en-bloc resected, the patient could still achieve long-term survival. The patient who underwent concomitant SVC and innominate vein resection and reconstruction with the longest survival in our series is still well without recurrence, 10 years 9 months postoperatively. We only precluded SVC resection and reconstruction (1) when metastasis was defined, (2) in prominent SVC syndrome, and (3) if there was extensive local invasion that prevented the tumor from being completely resected. Our data also revealed that survival was significantly better in the patients without aorta or pulmonary vessel involvement, and the survival curve continued to diverge throughout long-term follow-up. Thymic carcinoma with aorta or pulmonary vessel involvement always precluded complete resection, not only because it extensively encased the great vessels, but also because distant metastasis was frequently noted. These patients may have had early distant metastasis because the tumor cells penetrated and spread from the great vessels.

Our data also showed that Masaoka staging could not predict the prognosis of these patients, as reported in the literature [12]. This may be because stage III contains variable organ invasion, which would separately influence prognosis. Should involvement of the great vessels be upgraded to stage IV because it indicates poor prognosis? We tried to revise the stage but failed. This may be due to a limited number of patients. The TMN system has been applied for thymic carcinoma [5, 20]. In this series, we found that the incidence of nodal metastasis (perithymic or paratracheal) was relatively rare, and nodal status did not influence prognosis. 


\section{Conclusion}

Complete resection of thymic carcinoma is still the best way to achieve long-term survival. The patients with tumor invasion of the SVC, pulmonary vessels, or aorta have a poor prognosis.

\section{References}

1. Snover DC, Levine GD, Rosai J. Thymic carcinoma-five distinctive histological variants. Am J Surg Pathol 1982;6: 451-70.

2. Kirchner T, Muller-Hermelink HK. New approaches to the diagnosis of thymic epithelial tumors. Prog Surg Pathol 1989;10:167-89.

3. Suster S, Moran CA. Thymic carcinoma: spectrum of differentiation and histologic types. Pathology 1998;30:111-2.

4. Ritter JH, Wick MR. Primary carcinoma of the thymus gland. Semin Diagn Pathol 1999;1(16):18-31.

5. Suster S, Moran CA. Thymoma, atypical thymoma and thymic carcinoma. Am J Clin Pathol 1999;111:826-33.

6. Suster S, Rosai J. Thymic carcinoma-a clinicopathologic study of 60 patients. Cancer 1991;67:1025-32.

7. Chung DA. Thymic carcinoma-analysis of nineteen clinicopathological studies. Thorac Cardiov Surg 2000;48:114-9.

8. Chang HK, Wang $\mathrm{CH}$, Liaw CC, et al. Prognosis of thymic carcinoma: analysis of 16 patients. J Formosan Med Assoc 1992;91:764-9.

9. Liu HC, Hsu WH, Chen YJ, et al. Primary thymic carcinoma. Ann Thorac Surg 2002;73:1076-81.

10. Hsu HC, Huang EY, Wang CJ, et al. Postoperative radiotherapy in thymic carcinoma: treatment results and prognostic factors. Int J Radiat Oncol Biol Phys 2002;52(3):801-5.
11. Hsu CP, Chen CY, Chen CL, et al. Thymic carcinoma: ten years experiences in twenty patients. J Thorac Cardiovasc Surg 1994;107:615-20.

12. Blumberg D, Burt ME, Bains MS, et al. Thymic carcinoma: current staging does not predict prognosis. J Thorac Cardiovasc Surg 1998;115:303-9.

13. Chen FF, Yan JJ, Chang KC, Lai WW, Chen RM, Jin YT. Immunohistochemical localization of Mcl-1 and bcl-2 proteins in thymic epithelial tumours. Histopathology 1996; 29(6):541-7.

14. Chen FF, Yan JJ, Jin YT, Su IJ. Detection of bcl-2 and p53 in thymoma: expression of bcl-2 as a reliable marker of tumor aggressiveness. Hum Pathol 1996;27(10):1089-92.

15. Lai WW, Wu MH, Chou NS, et al. Surgery for malignant involvement of the superior vena cava. J Formosan Med Assoc 1992;91:991-5.

16. Suster S, Moran CA. Primary thymic epithelial neoplasm showing combined features of thymoma and thymic carcinoma: a clinicopathologic study of 22 patients. Am J Surg Pathol 1996;20(12):1469-80.

17. Masaoka A, Yamakawa Y, Fujii Y. Well-differentiated thymic carcinoma: is it thymic carcinoma or not? J Thorac Cardiovasc Surg 1999;117:628-30.

18. Weide LG, Ulbright TM, Loehrer PJ, et al. Thymic carcinoma-a distinct clinical entity responsive to chemotherapy. Cancer 1993;71:1219-23.

19. Lucchi M, Mussi A, Basolo F, et al. The multimodality treatment of thymic carcinoma. Euro J Cadiothorac Surg 2001;19:566-9.

20. Tsuchiya $R$, Koga $K$, Matsuno $T$, et al. Thymic carcinoma: proposal for pathological TMN and staging. Pathol Int 1994; 44:505-12. 